\title{
Biología reproductiva de Rhinobatos percellens (Walbaum, 1792) (Batoidea: Rajiformes) en el Caribe colombiano
}

\author{
Reproductive biology of Rhinobatos percellens (Walbaum, 1792) \\ (Batoidea: Rajiformes) from the Colombian Caribbean \\ Marcela Grijalba-Bendeck ${ }^{1}$, Arturo Acero P. ${ }^{2}$ y Esperanza González ${ }^{1}$ \\ ${ }^{1}$ Universidad de Bogotá Jorge Tadeo Lozano, Facultad de Ciencias Naturales, Programa de Biología Marina, \\ Santa Marta, Colombia \\ ${ }^{2}$ Universidad Nacional de Colombia, (Instituto de Ciencias Naturales), CECIMAR/ INVEMAR, \\ Cerro Punta Betín, Santa Marta, Colombia \\ marcela.grijalba@utadeo.edu.co
}

\begin{abstract}
The reproductive condition of 172 guitarfish Rhinobatos percellens was evaluated in animals incidentally captured in the captures of chinchorro playero between August 2005 and October 2006 at Salguero beach on Santa Marta, Colombia. To understand the reproductive cycle and how it is influenced by the environmental conditions, the reproductive systems were described. The guitarfish is a viviparous matrotrophic ray, with compound ovaries. Four ovarian developmental stages and nine espermatogenic phases of compound testis were observed. The vitellogenetic development was simultaneous to embryonic growth, with an active reproductive (matting, births, gestation) period between October and April, and a reduction in activity from May to September when embryos stop their growth. North hemisphere rhinobatids show an inverse cycle. Guitarfish females produced between two and four embryos with a gestation period of ten months from April to December; maternal size did not have any relation with embryo length and number. Biological indexes (gonadosomatic, hepatosomatic and condition factor) did not show clear time tendencies in relation to reproductive dynamics; they must be analyzed altogether with environmental condition and food availability.
\end{abstract}

Key words: Rhinobatidae, guitarfish, bioecology, gonadal structure, Colombia

\section{Introducción}

En las rayas, la presencia de especializados sistemas sensoriales, la fertilización interna y el desarrollo embrionario vivíparo aplacentario, entre otros (NOAA 1991), son adaptaciones que les han permitido sobrevivir con éxito por millones de años. No obstante, los batoideos son poblacionalmente vulnerables debido a varias características biológicas, como tasas de crecimiento corporal lentas, madurez sexual a edades tardías y bajas fecundidades. En consecuencia, los batoideos presentan un potencial reproductivo bajo, haciéndolos
Resumen.- Se evaluó la condición reproductiva de 172 rayas guitarra Rhinobatos percellens extraídas como fauna incidental de las capturas de chinchorro playero entre agosto 2005 y octubre 2006 en playa Salguero, Santa Marta, Colombia. Se describió la estructrura del sistema reproductor y la incidencia que sobre el ciclo reproductivo ejerce la condición ambiental. La raya guitarra es matrotrófica vivípara, con ovarios compuestos. El desarrollo ovocitario se compone de cuatro etapas y el de los testículos, que son compuestos, de nueve estados espermatogénicos. Se evidenció desarrollo vitelogenético simultáneo al crecimiento embrionario con un periodo de reproducción activa (cópula, nacimiento, gestación) entre octubre y abril y un receso de mayo a septiembre, durante el cual, al parecer, ocurre la diapausa embrionaria; este es inverso en términos de tiempo al descrito en la literatura para rinobátidos del hemisferio norte. En el Caribe de Colombia, las hembras gestan de dos a cuatro embriones entre dos y diez meses de abril a diciembre, sin que exista una relación de su talla y número, con el tamaño materno. El comportamiento de los índices biológicos (gonadosomático, hepatosomático y factor de condición) permitió comprender la dinámica reproductiva, pero no reveló tendencias marcadas en el tiempo, que deberán ser evaluadas en profundidad considerando la condición ambiental y la disponibilidad de alimento.

Palabras clave: Rhinobatidae, pez guitarra, bioecología, estructura gonadal, Colombia particularmente vulnerables a la sobreexplotación pesquera. Por ello, los trabajos bioecológicos profundos y detallados son fundamentales para valorar el estado actual de una población y explorar posiblidades para recuperarlas cuando estén en decaimiento (por causas naturales o antrópicas) (Bonfil 1994). En estudios reproductivos de peces, la disposición celular permite confirmar los estados de desarrollo gonadal y esclarecer los mecanismos que rigen sus ciclos reproductivos, en los cuales participan complejas estructuras como la glándula nidamental y útero. A pesar de la información que estas estructuras presentan, su conocimiento es básico, 
de hecho, muy poco se conoce sobre la biología reproductiva de las especies que habitan ambientes tropicales.

La microestructura del sistema reproductivo en condrictios ha sido estudiada por Pratt (1988) quien destacó la importancia de estas evaluaciones para esclarecer las relaciones filogenéticas de los peces cartilaginosos. Otros autores, como Jezior \& Hamlett (1994) y Hamlett et al. (1996, 1999), describieron la estructura de los folículos del ovario en Urolophus jamaicensis y Dasyatis americana, basada en la descripción de los tipos de células y tejidos que componen el trofonemata para estas especies, encontrando marcadas diferencias con otras como Rhinoptera bonasus y Myliobatis sp.

Los hábitos reproductivos para $R$. percellens han sido mencionados sólo de manera descriptiva, pero no hay estudios puntuales en Colombia. Cervigón \& Alcalá (1999) en Venezuela equivocadamente atribuyen al género un tipo de reproducción ovípara; sin embargo, Téllez et al. (2006) y Acevedo et al. (2007) claramente proponen una reproducción matotrófica vivípara para la especie en playa Salguero, Santa Marta; es así como el presente estudio tiene como objetivo describir macro y microestructuralmente el sistema reproductor de la raya guitarra $R$. percellens. Además, se analiza la dinámica espacio-temporal de la especie en el margen costero del Departamento de Magdalena, Caribe de Colombia.

\section{Material y métodos}

\section{Muestreo en campo}

El estudio se llevó a cabo en playa Salguero que se sitúa en el margen izquierdo de la desembocadura del río Gaira, que se localiza a $6 \mathrm{~km}$ al suroeste de Santa Marta (11 ${ }^{\circ} 10^{\prime}$ $11^{\circ} 11^{\prime} \mathrm{N} ; 7^{\circ} 13^{\prime}-74^{\circ} 14^{\prime} \mathrm{W}$ ) (Fig. 1). En ella se desarrolla una importante actividad pesquera artesanal en la que se emplea principalmente el chinchorro de arrastre o playero (INVEMAR 2000).

Playa Salguero se encuentra bajo la influencia del patrón climático típico de la costa Caribe, con dos épocas climáticas claras, época seca mayor (diciembre-marzo) caracterizada por la influencia de los alisios y la corriente Caribe y la época lluviosa mayor (abril-noviembre). La costa es de pendiente suave con playas litoclásticas, debido a los aportes de la Ciénaga Grande de Santa Marta (CGSM) y del río Magdalena.

Los ejemplares provienen de la pesca artesanal efectuada con chinchorro de arrastre en playa Salguero, entre agosto 2005 y octubre 2006. Los chinchorros

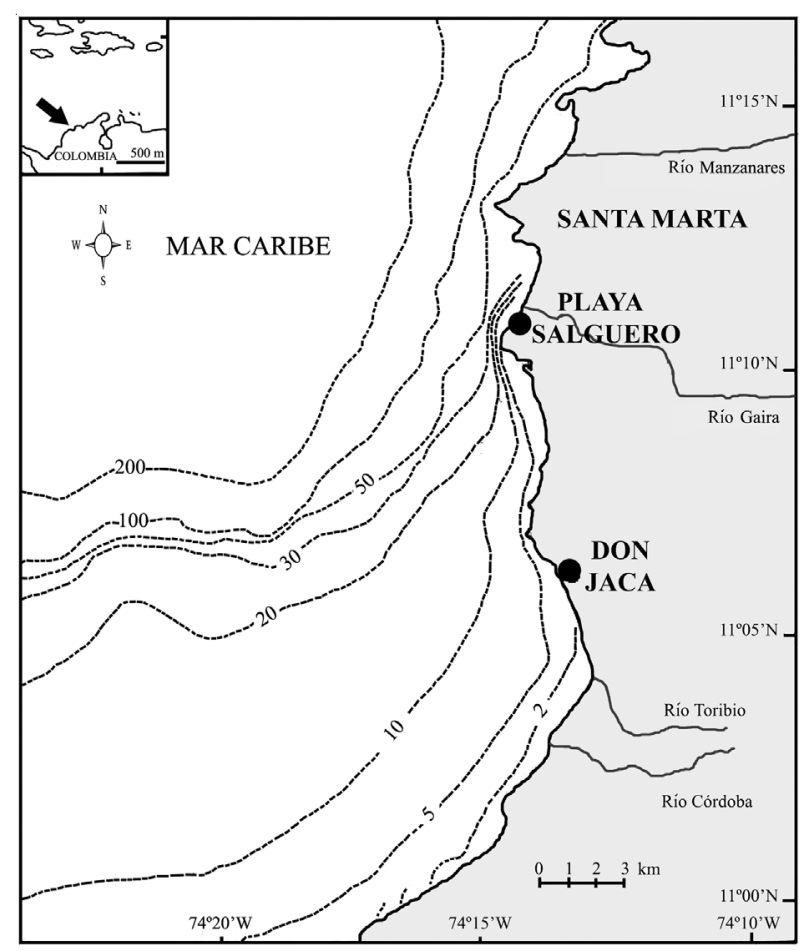

Figura 1

Área de estudio con la ubicación geográfica de playa Salguero y Don Jaca, en Santa Marta, Caribe colombiano

Study area representing the geographic location of Salguero beach and Don Jaca, Santa Marta, Colombian Caribbean

empleados presentaron mangas de $150 \mathrm{~m}$ con un tamaño de malla de $5 \mathrm{~cm}$ y $3 \mathrm{~cm}$ en el copo, ambos elaborados en náilon multifilamento, cada manga con 60 plomos y 60 flotadores, cada lance tuvo una duración aproximada de una hora y se caló a 350 - $400 \mathrm{~m}$ de la costa. De cada espécimen se tomaron datos morfométricos tales como la longitud total (LT), longitud del disco (LD), ancho del disco (AD) y peso total (PT).

\section{Análisis de laboratorio}

Los ovarios y testículos se pesaron y analizaron macroscópicamente para determinar su estado de desarrollo (Tabla 1). En el caso de los machos se determinó la longitud del órgano copulador desde su punto de inserción interno hasta su extremo distal, su grado de calcificación, capacidad de rotación y la presencia de material espermático. Para las hembras se midió el grosor de la pared del útero, la diferenciación de los oviductos, desarrollo de la glándula nidamental y presencia de 
Tabla 1

Escala de desarrollo gonadal adaptada para peces cartilaginosos (modificada de Holden \& Raitt 1975, Natanson \& Cailliet 1986, Snelson et al. 1988, Tresierra \& Culquichicón 1993 y Acuña et al. 2001)

Gonadal development scale adapted for cartilaginous fishes (modified from Holden \& Raitt 1975, Natanson \& Cailliet 1986, Snelson et al. 1988, Tresierra \& Culquichicon 1993, and Acuña et al. 2001)

\begin{tabular}{cl}
\hline I & \multicolumn{1}{c}{ HEMBRAS } \\
\hline II $\quad \begin{array}{l}\text { Inmadura: Sin desarrollo ovárico, ovarios pequeños de textura acuosa, oviductos delgados poco } \\
\text { diferenciados } \\
\text { En maduración: Ovarios delgados, consistentes y de apariencia uniforme, sin ovocitos visibles, } \\
\text { oviductos delgados y diferenciables } \\
\text { Madura sin embriones: Ovario con ovocitos visibles, oviductos gruesos y útero parcialmente } \\
\text { ensanchado } \\
\text { IIIa }\end{array}$ Madura con embriones: Ovarios con ovocitos, embriones ubicados dentro de los úteros, que se \\
encuentran ensanchados, ocupando gran parte de la cavidad visceral \\
IIIb $\begin{array}{l}\text { Maduras postparto: Útero ensanchado con paredes sanguinolientas y flácidas. Abertura cloacal } \\
\text { expandida }\end{array}$ \\
\hline II $\quad \begin{array}{l}\text { Inmaduro: Testículos acuosos, ductos poco diferenciados, clásper pequeños, flácidos, rifiodón } \\
\text { cerrado, ausencia de semen y rotación menor a } 360^{\circ}\end{array}$ \\
$\begin{array}{l}\text { En maduración: Testículos consistentes, ductos bien desarrollados, epidídimos enrollados en la } \\
\text { porción anterior y media, del ducto eferente, clásper aumentan de tamaño y están parcialmente } \\
\text { calcificados } \\
\text { Maduro: Testículos con lóbulos prominentes indicativos de activa producción espermática, } \\
\text { conducto deferente se extiende adyacente a la columna vertebral, epidídimo enrollado a lo largo de } \\
\text { todo el conducto hasta llegar a la vesícula seminal, clásper totalmente calcificados, con rifiodón } \\
\text { abierto y presencia de semen }\end{array}$ \\
III
\end{tabular}

huevos. Finalmente, las gónadas analizadas se conservaron en formalina al 10\% (Snelson et al. 1988) y se almacenaron en alcohol isopropílico al 40\% (Natanson \& Cailliet 1986). Se prepararon muestras histológicas de ovario, glándula nidamental y útero para las hembras; y testículos, epidídimos, ductos deferentes y vesícula seminal para los machos. Se aplicó la técnica descrita por Martoja \& Martoja-Pierson (1970), teñidas en sucesivas soluciones de Hematoxilina-Eosina de Harris y por el método del ácido peryódico del reactivo de Schiff (PAS). Se realizaron descripciones histológicas teniendo en cuenta los criterios de Pratt (1988) por cada estado de madurez en el tiempo.

La fecundidad se estableció a partir del conteo del número de crías por hembra (Conrath 2005). El grado de desarrollo embrionario se determinó usando la escala de Mollet et al. (1999), además de otros aspectos de morfología externa como presencia de filamentos branquiales, dientes y saco vitelino (Liu et al. 1999). De esta manera se reconocieron tres estados: temprano, medio y tardío, asumiendo que para la mayoría de rayas la talla de nacimiento es menor al $20 \%$ del tamaño materno.

\section{Análisis de la información}

El periodo de gestación y época de nacimiento se determinaron a partir del análisis del número de hembras grávidas conteniendo embriones en estado tardío de desarrollo (White et al. 2001), y verificando la presencia de juveniles con marcas de nacimiento. Los meses con mayor número de embriones, de mayores longitudes y con grados de desarrollo tardío fueron considerados momentos de nacimiento. El periodo de gestación se sugirió con base en el incremento de la proporción de hembras preñadas y mediante el análisis del desarrollo embrionario.

La proporción de sexos en juveniles y adultos se estimó mensualmente como una razón del número de machos/hembras, se presentó de manera gráfica siguiendo lo propuesto por Tresierra \& Culquichicón (1993), para determinar si presentaron diferencias entre la proporción observada con la esperada de 1:1, la cual es característica de muchos vertebrados al nacer e indica posible segregación espacio temporal por sexos (Tresierra \& Culquichicón 1993); se empleó la prueba Chi-cuadrado con un nivel de confianza del 95\% $(P>0,1)$. 
La talla de primera madurez se estableció en cada sexo, como la talla del individuo maduro más pequeño (Conrath 2005) y la talla media de madurez, a partir del ajuste de la función logística de la proporción de individuos maduros; la curva fue ajustada empleando la técnica de regresión no lineal propuesta por Saila et al. (1988) en el programa S-PLUS (2000). La talla media se estableció a partir del L $50 \%=-\mathrm{a} / \mathrm{b}$ y se calculó con relación a la longitud total, con el fin de realizar comparaciones con otras especies de rinobátidos, de acuerdo a $\mathrm{P}(\mathrm{l})=[1 /(1+\mathrm{e}(\mathrm{a}+\mathrm{bl}))]$, donde $\mathrm{Pl}$ : proporción de individuos maduros, a y b: constantes y l: intervalo de tallas (Tresierra \& Culquichicón 1993). En machos también se evaluó la relación entre la longitud del clásper y la longitud total (Natanson \& Cailliet 1986, Martín \& Cailliet 1988, Timmons \& Bray 1997). La talla de nacimiento se calculó a partir del promedio entre la talla (Lt) del embrión de mayor tamaño encontrado en el útero, con la talla (Lt y AD) del individuo más pequeño capturado (Conrath 2005).

A partir del peso total y para evaluar la condición reproductiva se calcularon los índices biológicos propuestos por Tresierra \& Culquichicón (1993), gonadosomático (IGS), que establece los periodos de alta actividad reproductiva, el índice hepatosomático (IHS) y el factor de condición (FC), que representan una aproximación al grado de bienestar para eventos reproductivos. La época probable de nacimientos se estableció calculando las frecuencias numéricas y porcentajes mensuales de los diferentes estados de desarrollo gonadal de ovarios y testículos; con esta información se realizó la descripción del ciclo reproductivo de $R$. percellens.

\section{Resultados}

Se capturaron 172 rayas guitarra; 85 ejemplares fueron hembras y 87 machos, definiendo una proporción sexual $0,98: 1$, que no es significativamente diferente de $1: 1$ $(P=0,01652)$. Las longitudes corporales (de aquí en adelante llamadas 'tallas') se encontraron entre $174 \mathrm{~mm}$ a $609 \mathrm{~mm}$ para machos y de 170 a 735 para hembras. Se observó una leve dominancia de las hembras durante los meses de julio y septiembre, mientras que en agosto de 2006 solo se encontraron machos (Fig. 2).

\section{Sistema reproductor de hembras}

Está conformado por un par de ovarios y úteros funcionales; macroscópicamente los ovarios se definen como externos, y se suspenden directamente del mesovario, pueden encontrarse adosados al órgano

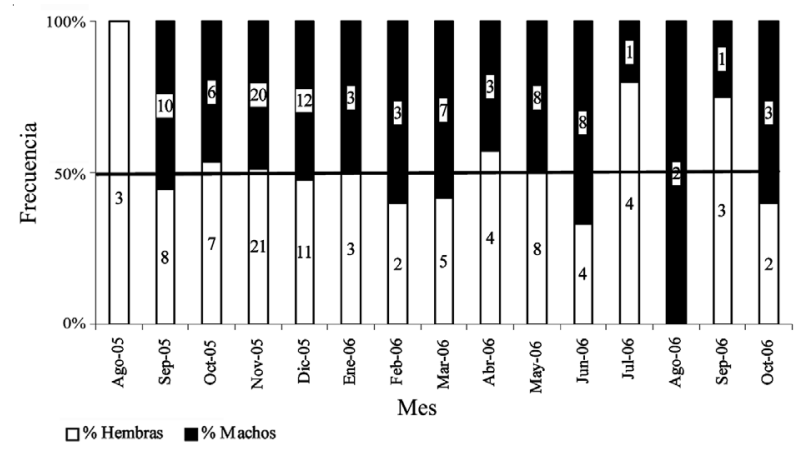

Figura 2

Proporción sexual por mes de $\boldsymbol{R}$. percellens, entre agosto 2005 y octubre 2006. La línea roja representa una proporción equitativa de hembras y machos

Monthly sexual proportion of $R$. percellens, between August 2005 and October 2006. The red line represents the same proportion of males and females

epigonal, que es reducido en ejemplares maduros o ausente en los juveniles. Cada ovario produce grupos de ovocitos similares en peso y tamaño, solo uno de los grupos se desarrolla a la vez. Los estados inmaduros se caracterizaron por presentar ovarios comprimidos y alargados con mayor abundancia de ovocitos pequeños ( $<3 \mathrm{~mm}$ en diámetro) pero visibles, los oviductos aparecieron muy delgados y largos. En animales maduros se observaron ovocitos de mayor tamaño ( $>3,1 \mathrm{~mm})$, los oviductos se encontraron ensanchados en animales en estado IIIb y IV. En 13 hembras con longitudes totales por encima de $497 \mathrm{~mm}$ se registró la presencia de las glándulas nidamentales u oviducales. A cada lado del cuerpo y contiguo a la glándula está el útero, que aparece como un ensanchamiento del oviducto y se abre en lo que Wenbin \& Shuyuan (1993) denominan vagina, la cual a su vez se comunica con el atrio común o cloaca.

\section{Análisis microestructural del sistema reproductor en} hembras

Los ovarios de hembras inmaduras (I) de $R$. percellens están conformados por tejido conjuntivo y fibras de colágeno; no se observó tejido epitelial ni la capa albugínea típica de peces óseos. En el interior del ovario se encontraron ovocitos circulares en diversos estados de desarrollo y distinto tamaño, los folículos inmaduros se distribuyeron en mayor proporción en la parte central del ovario y los maduros hacia los conductos internos y la periferia. En la parte posterior de los ovarios se registraron granulaciones y no se observaron folículos en ningún estado de desarrollo. 
Para los ovocitos de $R$. percellens se definieron cuatro etapas de desarrollo: 1) Ovocitos con el núcleo y nucleolo visibles, este último se puede encontrar hacia uno de los bordes de la membrana nuclear y pueden ser entre uno y seis. Ovocito rodeado por epitelio plano simple, que se transforma en epitelio cúbico y capas de tejido conjuntivo (Fig. 3A); 2) Ovocitos rodeados de zona pelúcida (membrana acelular), seguida de un epitelio cúbico simple, se diferencia el núcleo con un nucléolo (Fig. 3B), 3) Ovocitos bordeados por la zona pelúcida, rodeada de células cúbicas, que se van transformando en un epitelio columnar simple y externamente tejido conjuntivo laxo con fibroblastos y fibras de colágeno, no son visibles los nucleolos (Fig. 3C) y 4) Ovocitos conteniendo gránulos de vitelo, cubiertos por una gruesa zona pelúcida bordeada por epitelio columnar y tejido conjuntivo laxo, se diferencian fibroblastos. En esta etapa la capa de células columnares pierde la forma, el grosor de la capa aumenta y los núcleos aparecen en diferente posición, a medida que se engrosa la pared del folículo, aumenta el número de células secretoras dentro de ella; así mismo, los gránulos de vitelo se van madurando y agrandando hasta que el ovocito queda completamente lleno de estos. El epitelio secretor está constituído por células redondeadas, grandes, con abundante citoplasma, núcleo redondeado y presencia de un nucléolo (Fig. 3D). El ovocito maduro en el interior del ovario alcanza un tamaño de $10 \mathrm{~mm}$ y fuera crece hasta $28,8 \mathrm{~mm}$, el folículo presenta una pared gruesa y está conformado por los mismos tejidos y características de la cuarta etapa (Fig. 3E).

El ovario está bordeado por tejido conjuntivo; rodeando los conductos se reconoce tejido columnar simple y epitelio pseudoestratificado ciliado, otros están recubiertos por células cúbicas. Los conductos están inmersos en tejido conjuntivo laxo a través del cual los ovocitos migran. Al madurar un folículo, se desarrolla un estoma en el peritoneo de la superficie ovárica a través del cual pasa el ovocito para luego desprenderse y buscar el ostium; la alta abundancia de ovocitos maduros en la superficie ovárica categoriza los ovarios de la raya guitarra como externos (Pratt 1988).

Las glándulas nidamentales son estructuras donde se almacenan los espermatozoides y aunque no se registraron conteniendo este material, se estima que este puede permanecer allí entre pocos días y varios años (Maruska et al. 1996). En la raya guitarra esta estructura presentó forma ovalada, recubierta por músculo liso y conteniendo porciones glandulares circulares y alargadas, irrigadas por capilares. Estas porciones están provistas de una membrana basal que nutre las células, epitelio cúbico basal y columnar simple de recubrimiento (Fig. 3F).
También se corroboró la subdivisión de la glándula nidamental en una porción secretora de albúmina y otra productora de la cáscara y la disposición de túbulos secretores en su interior; sin embargo, su forma acorazonada como se cita para $H$. hynnicephalus (Wenbin \& Shuyuan 1993), no logró ser evidenciada.

El útero de la raya guitarra en su interior evidenció numerosos pliegues que determinan su capacidad de ensancharse para albergar los huevos; cuando está expandido sus paredes son delgadas y muy vascularizadas. El útero maduro, en su parte posterior, contiene gránulos de vitelo y porciones glandulares que alternan con tejido conjuntivo laxo. En la parte anterior se diferencian dos zonas, una netamente glandular con tres regiones definidas por coloración y presencia de gránulos, y la segunda donde prevalecen conductos rodeados de epitelio pseudoestratificado ciliado. En la luz del útero se observaron pliegues conformados por porciones glandulares de tipo calciforme, además de tejido conjuntivo y túbulos glandulares, alternando con vasos sanguíneos y epitelio columnar provisto de microvellosidades, que aportan suplemento nutritivo a los embriones por secreción del fluido uterino (Fig. 3G y $3 \mathrm{H})$.

\section{Análisis de la condición reproductiva en hembras}

La raya guitarra mostró representatividad de todos los estados de desarrollo gonadal en playa Salguero, con mayor número de ejemplares en el estado inmaduro I $(82 \%)$, precedido por hembras maduras con embriones IIIb (9,4\%); las hembras maduras se vieron conteniendo ovocitos con diámetros entre 13 y $27,8 \mathrm{~mm}$ y alcanzaron su madurez a los $474 \mathrm{~mm}$ de longitud total. La hembra madura más pequeña sin embriones midió $542 \mathrm{~mm}$, la de menor tamaño con embriones fue de $561 \mathrm{~mm}$ y talla media de madurez calculada en el presente estudio fue $474 \mathrm{~mm}$ en hembras; no obstante, la baja representatividad de ejemplares de menos de $560 \mathrm{~mm}$ puede estar sesgando esta determinación.

Los huevos más grandes se presentaron dos veces en el año; los embriones más pequeños se encontraron en diciembre 2005 y los más grandes en marzo 2006, ubicados con la cabeza orientada hacia la abertura cloacal. Las envolturas se registraron con embriones de 75 a 76 $\mathrm{mm}$ de longitud total, pero no se vieron recubriéndolos, lo cual sugiere que las cubiertas se rompen y enrollan cuando el embrión está entre 70 y $75 \mathrm{~mm}$; éstas al parecer se reducen y reabsorben en un proceso que no es claramente conocido. El hecho de haberse encontrado embriones en variados estados de desarrollo durante varios meses, dificultó determinar a ciencia cierta el 

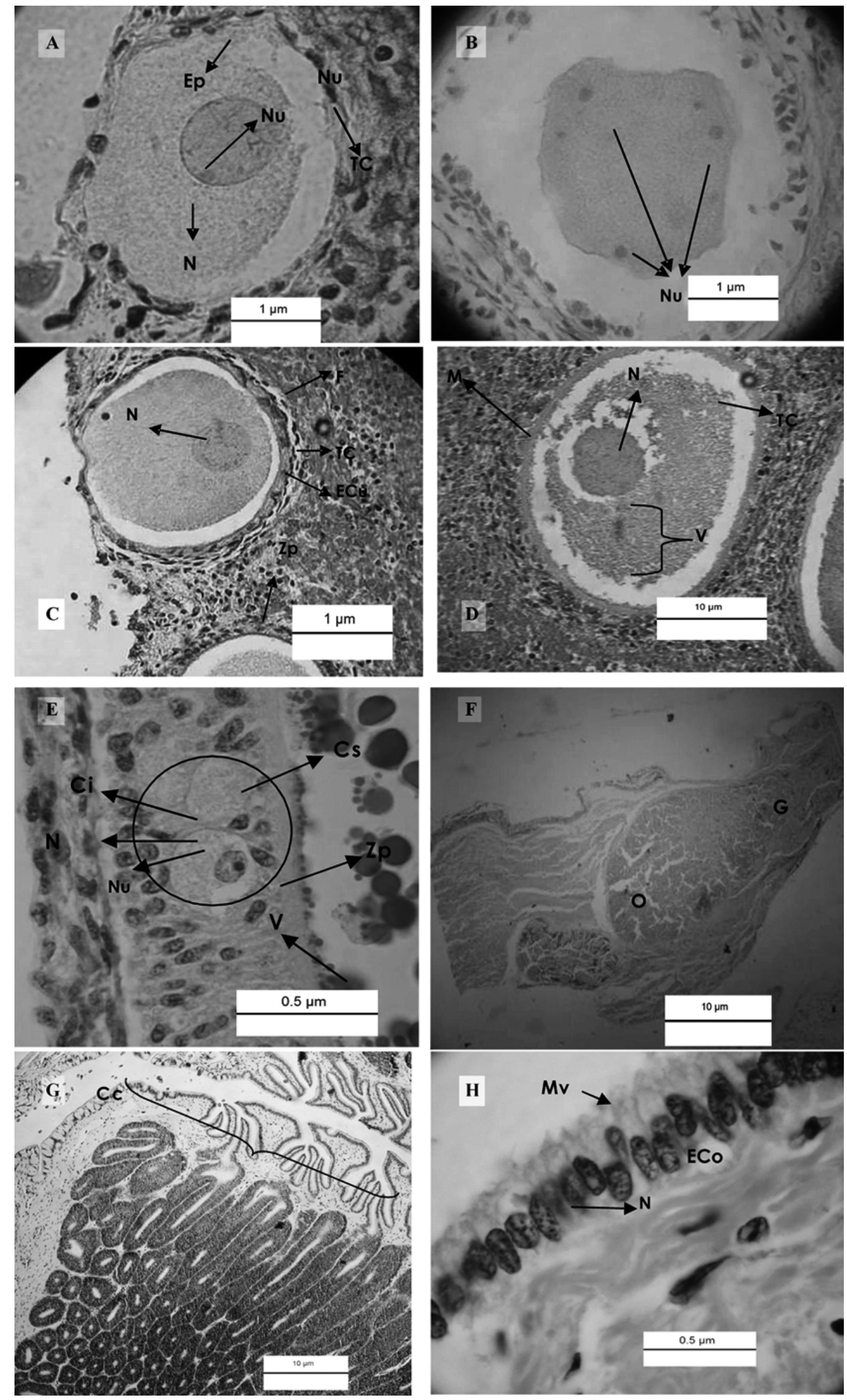
Figura 3

Etapas del desarrollo ovocitario en $R$. percellens capturada en Santa Marta, Caribe, Colombia. A, primera etapa. Núcleo (N), nucleolo (Nu), epitelio plano simple (Ep) y tejido conjuntivo laxo (TC). B, segunda etapa. Ovocito conteniendo numerosos nucleolos $(\mathrm{Nu})$. C, tercera etapa. Se observa la zona pelúcida ( $\mathrm{Zp}$ ), núcleo, epitelio cúbico (ECu) y tejido conjuntivo laxo con fibroblastos (F). D, cuarta etapa. Núcleo, membrana celular (M), epitelio columnar (ECo), tejido conjuntivo con fibroblastos y vitelo (V). E, Corte ovocitario mostrando vitelo, zona pelúcida (ZP), citoplasma (Ci), células secretoras (Cs), núcleo y nucleolo. F, ovocito maduro con porción granular (O) y glandular (G). G, corte de glándula nidamental provista de conducto central $(\mathrm{Cc})$ y secundarios. $\mathrm{H}$, pared uterina con epitelio columnar simple, núcleo (N) y microvellosidades (Mv)

Oocyte development stages of $R$. percellens captured at Santa Marta, Caribbean, Colombia. A, first stage. Nucleus (N), nucleolus $(\mathrm{Nu})$, simple flat epithelium (Ep) and conjunctive lax tissue (TC). B, second stage. Oocyte containing numerous nucleoli (Nu). $\mathrm{C}$, third stage. The pellucid zone (Zp), nucleus, cubical epithelium (ECu) and conjunctive lax tissue with fibroblasts (F) are observed. D, fourth stage. Nucleus, cellular membrane (M), columnar epithelium (ECo), conjunctive tissue with fibroblast and vitellus (V), E, oocyte section showing vitellus, pellucid zone (ZP), cytoplasm (Ci), secretory cells (Cs), nucleus and nucleolus. F, mature oocyte with granular $(\mathrm{O})$ and glandular $(\mathrm{G})$ portions. $\mathrm{G}$, section of nidamental gland with central

$(\mathrm{Cc})$ and secondary ducts. $\mathrm{H}$, uterine wall with simple columnar epithelium. nucleus $(\mathrm{N})$ and microvilli $(\mathrm{Mv})$

tiempo de duración de su desarrollo en el interior de la madre, el cual puede ser de dos a tres meses, pero por la reproducción constante que ocurre entre octubre y abril, es posible que tenga una duración mayor y que se vea limitado por una fase de diapausa, descrita para otros batoideos.

De los 33 embriones analizados 15 fueron hembras y 18 machos, por su estado de desarrollo se categorizanon en estadío tres, cuatro y cinco, no se encontró relación significativa entre la longitud materna y la talla (r2= 0,012), el número de ovocitos ( $\mathrm{r} 2=0,011)$, el número de embriones ( $\mathrm{r} 2=0,24)$, y talla de los embriones $(\mathrm{r} 2=0,02)$.

\section{Sistema reproductor en machos}

El sistema reproductor de machos estuvo conformado por dos cláspers calcificados, con el rifiodón abierto en animales maduros, internamente un par de testículos funcionales alargados y comprimidos dorso-ventralmente con 10-12 lóbulos. En machos maduros los testículos alcanzaron $35 \mathrm{~mm}$, los órganos epigonales se desarrollan en el extremo final del testículo y recubren toda la superficie anterior (delgada y translúcida en machos juveniles y rojiza y esponjosa en adultos). Los vasos eferentes conectan los testículos con los epidídimos, los túbulos del epididimo se observaron muy enrollados, pero se enderezan en la porción final formando los vasos deferentes que dan origen a la vesícula seminal, la que a su vez tranfiere el material seminal y los espermatozoides a la glándula del clásper.

\section{Microestructura del sistema reproductor en machos}

Los testículos se observaron comprimidos de bordes redondeados, los cortes transversales mostraron alrededor del testículo una delgada pared de tejido conjuntivo y el órgano epigonal rojizo, ambos se unen al mesorquio que da soporte a la matriz folicular. En animales inmaduros los cortes de la porción anterior de la vesícula seminal estuvieron conformados por tejido glandular y conjuntivo laxo. Machos en maduración presentaron en la parte media y posterior, granulaciones y un mayor número de cistos, todos en el mismo estado de desarrollo. En los machos maduros priman los cistos conteniendo espermatozoides maduros, en medio de estos se encuentra tejido conjuntivo y eritrocitos. Se definieron nueve etapas de desarrollo espermatogénico para la raya guitarra: 1) Cistos de forma circular, bordeados de tejido conjuntivo y fibroblastos; bordeando se observan las células espermáticas 'espermatogonias' también redondeadas, con diámetros cercanos a 1,2 ìm, conteniendo células germinativas de 0,15 ìm aproximadamente y cromatina granulosa basófila, acompañada de un número proporcional de células de Sertoli de 0,1 ìm y tejido conjuntivo; los nucleolos son visibles y de coloración rojiza (Fig. 4A), 2) Se incrementa el número de espermatogonias, la cromatina se hace menos granulosa y adquiere mayor densidad, las células de Sertoli se diferencian por su gran tamaño y coloración blanquecina, son aún visibles los nucleolos de color rojo oscuro (Fig. 4B), 3) Los cistos aumentan su diámetro (1,5 ìm), la cromatina adquiere un aspecto alargado y espiralado, son visibles los nucleolos y las células de Sertoli, estas últimas se reducen en cantidad, se aclaran y se ubican basalmente (Fig. 4C), 4) La célula espermática 'espermatocito', reduce su tamaño $(0,04$ ìm), la cromatina se ve condensada y reticulada, los cistos son grandes (1,7 ìm), y en los bordes siguen ubicadas las células de Sertoli (Fig. 4D), 5) Las células espermáticas se hacen más pequeñas y levemente alargadas, son visibles las células de Sertoli de gran tamaño en los márgenes del cisto, donde se ven separadas y desorganizadas, el diámetro del espermatocito no cambia con relación al estado anterior (Fig. 4E), 6) 

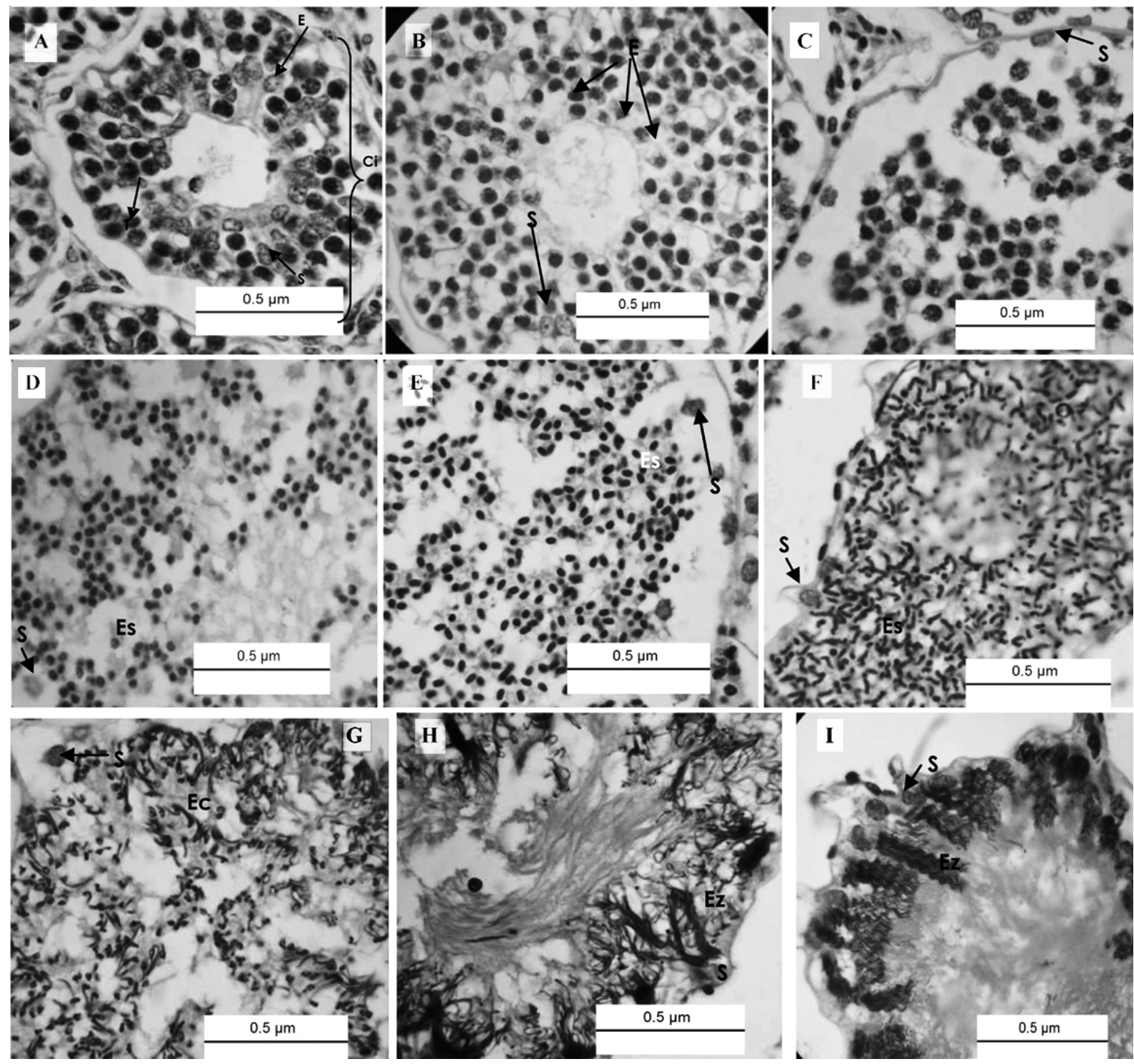

Figura 4

Fases del desarrollo espermatogénico de $R$. percellens del Caribe de Colombia. A, primera etapa. Espermatocitos (Ci), bordeados por tejido conjuntivo con fibroblastos (F), células de Sertoli (S) y espermatogonias (E). B, segunda etapa. C, tercera etapa. Espermatogonias (E) y células de Sertoli. D, cuarta etapa. Clara diferenciación de espermatocitos (Es)

y células de Sertoli (S). E, quinta etapa. Reducción de los espermatocitos y condensación de cromatina. F, sexta

etapa. Disminución del tamaño celular y claro alargamiento, formando cabeza y cola, sin diferenciación del cuello, reducción de las células de Sertoli. G, séptima etapa. Espermátidas (Ec) alineadas y células de Sertoli (S). H, octava etapa. Espermatozoides (Ez) visibles organizados y células de Sertoli en la periferia. I, novena etapa. Espermatozoides completamente maduros junto con células de Sertoli, algunas de las cuales ya han vaciado su contenido

Spermatogenic development stages of $R$. percellens of the Caribbean Colombia. A, first stage. Spermatocytes (Ci), bordered by conjunctive tissue with fibroblasts (F), Sertoli cells (S) and spermatogonia (E). B, second stage. C, third stage. Spermatogonia

(E) and Sertoli cells. D, fourth stage. Clear differentiation of spermatocytes (Es) and Sertolli cells. E, fifth stage.

Spermatocytes reduction and cromatin condensation. F, sixth stage. Cell size reduction and clear extension, forming head and tail without differentiation of the neck, reduction of the Sertoli cells, G, seventh stage. Aligned spermatids (Ec) and Sertoli cells (S). H, eighth stage. Spermatozoa (Ez) visible and organized, and Sertoli cells on the periphery. I, ninth stage. Mature spermatozoa with Sertoli cells, some of which have already emptied their content 
En esta etapa comienza la fase de espermátida con fuerte reducción celular, la cromatina se alarga y comienza a describir la cabeza y la cola, sin la distinción del cuello, las células de Sertoli reducen su material citoplasmático y aún se observan hacia los márgenes del cisto (Fig. 4F), 7) La célula espermática continúa haciéndose más pequeña, la cabeza es marcadamente reducida y es evidente un notable alargamiento y adelgazamiento de la cola; comienza el alineamiento de las células al interior del cisto, algunas células de Sertoli siguen siendo evidentes, otras se han perdido (Fig. 4G), 8) La célula espermática adquiere la connotación de 'espermatozoide', las cabezas se observan muy pequeñas y contienen la cromatina muy condensada, esta se hace visible como puntos oscuros, la cola es larga y casi recta, los espermatozoides continúan su organización por paquetes y alrededor se diferencian bien las células de Sertoli (Fig. 4H) y 9) Los espermatozoides están completamente desarrollados, las cabezas son diminutos puntos oscuros de las cuales se desprenden las colas rizadas, forman paquetes cónicos denominados espermatozeugmata, que se orientan a través de la periferia del cisto y embeben en la región apical de las células de Sertoli, encargadas de la función de sostén y nutrición de los espermatozoides; cada una se asocia a una espermatozeugmata cuya ruptura inicia la liberación del esperma (espermiación) (Fig. 4I). El epidídimo en animales maduros aparece como paquetes de espermatozoides rizados y la vesícula seminal se observa recubierta por musculatura lisa, los ductos bordeados por epitelio conjuntivo y columnar se vieron contieniendo los espermatozoides, además, células sanguíneas, fibroblastos, tejido conjuntivo laxo, fibras de colágeno y células de Sertoli.

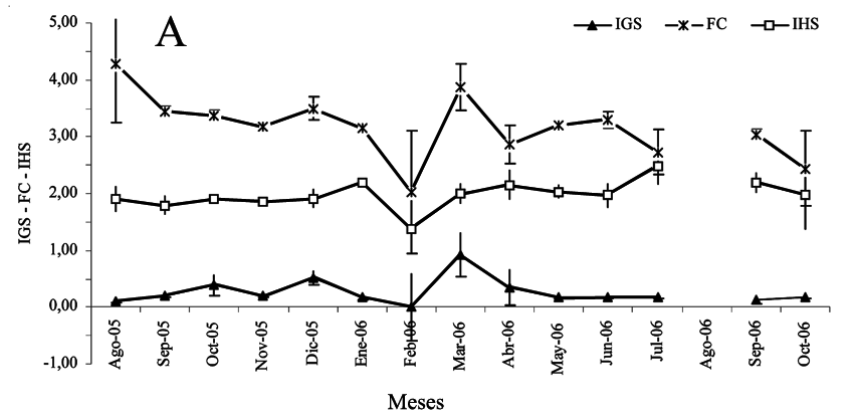

\section{Condición reproductiva en machos}

Los machos de raya guitarra mostraron, al igual que las hembras, mayor proporción de animales inmaduros I, que representaron el 55\% (48 ejemplares de los 87 analizados); seguidos por el estado maduro III, en el que se encontraron 25 individuos que correspondieron al $29 \%$. A nivel temporal se reveló la presencia casi permanente y simultánea de individuos inmaduros I y maduros III durante la mayor parte del tiempo en el área. La talla media de madurez para machos calculada a partir del método de ajuste de la función logística de los ejemplares en estado de madurez III fue 503,6 mm, superior a la evaluación con respecto a la longitud de los cláspers (445 $\mathrm{mm}$ ). La discrepancia entre estos resultados responde a la baja representatividad de las tallas comprendidas entre los 400 y $500 \mathrm{~mm}$, cuya evaluación hubiera demarcado mejor el cambio de la pendiente y por ende el inicio de la fase adulta.

\section{Índices biológicos}

Los tres índices biológicos calculados para hembras de raya guitarra mostraron una tendencia similar entre sí. El IGS presentó sus valores más altos en diciembre $(0,41 \pm$ $0,07)$, febrero $(1,44 \pm 0,01)$ y marzo $(0,36 \pm 0,11)$, que claramente responden a la presencia de hembras maduras. El IHS mantuvo un comportamiento estable, salvo dos leves incrementos en enero y julio, que pueden indicar un aumento en la reserva hepática y el FC no mostró modificaciones respecto al comportamiento ya descrito, con los valores más altos de febrero a abril. En machos el IGS tuvo un comportamiento casi lineal. El mayor registro del IHS se dio en enero $(2,84 \pm 1,23)$ y el FC arrojó los mayores valores entre septiembre y diciembre $2005(3,47$ $\pm 0,11$ y $3,46 \pm 0,25)$ (Fig 5).

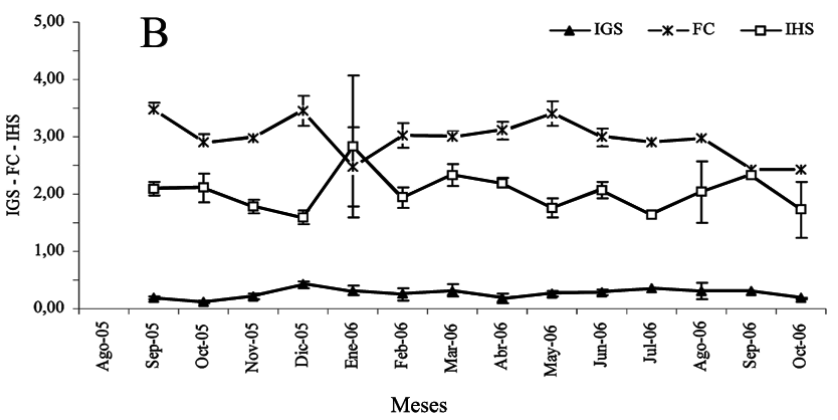

Figura 5

Fluctuación de los índices gonadosomático (IGS) y hepatosomático (IHS) y factor de condición (FC) en: A, hembras y B, machos de $R$. percellens capturadas incidentalmente con chinchorro en Santa Marta, Colombia

Fluctuation of gonadosomatic (IGS) and hepatosomatic (IHS) indexes and condition factor (FC) from: A, females and B, males of $R$. percellens incidentally captured with chinchorro at Santa Marta, Colombia 


\section{Discusión}

El sistema reproductor de la raya guitarra $R$. percellens presenta una estructura y funcionamiento similar al descrito para otros batoideos de regiones tropicales y subtropicales, categorizándose como vivípara aplacentada con modificaciones uterinas (trofonemata) que producen leche uterina (histiotrofo) que complementan la nutrición embrionaria. Los ovarios se catalogaron en un estado intermedio entre externo e interno y los testículos como compuestos, el desarrollo de los ovocitos ocurre en cuatro etapas y nueve se definieron en el desarrollo espermatogénico. La talla máxima registrada para las hembras fue $17,14 \%$ mayor respecto a la encontrada en el macho más grande, acorde a lo mencionado por Villavicencio-Garayzar (1995) para Z. exasperata.

El sistema reproductor de las hembras de la raya guitarra se asemeja a los descritos para $R$. horkeli (Wourms 1981), R. hynnicephalus (Wenbin \& Shuyuan 1993), $R$. productus (Villavicencio 1993a), R. cemiculus (Seck et al. 2004) y $R$. rhinobatos (Ismen et al. 2007). Se exceptúa la talla a la que se diferenció la glándula nidamental, que para $R$. percellens fue visible en animales que superaron el 67,6\% de su tamaño máximo (735 mm, presente estudio), levemente superior a $R$. hynnicephalus para la que se dio cuando las hembras alcanzaron $62,7 \%$ de su talla máxima (622 mm según Wenbin \& Shuyuan 1993).

Se asignó la categoría de ovario compuesto (Pratt 1988), como ha sido descrito para Batoidea, Squalomorphi, Squatinomorphii y Galeomorphii. Este es un carácter que al parecer evolucionó separadamente, lo que no ha sido totalmente estudiado, por lo cual debe ser útil en sistemática filogenética, junto a características moleculares y reproductivas, como la presencia de trofonemata. La simultaneidad en la vitelogenesis de los huevos y la presencia de embriones uterinos en $R$. percellens coincide además con el ciclo descrito para $R$. cemiculus y $R$. productus, para las cuales se presenta una única época reproductiva de abril a agosto, despues de la expulsión de las crías, las hembras ovulan y copulan, luego se mantienen en receso durante los meses restantes (Seck et al. 2004, Villavicencio 1993b). La consideración de cuatro etapas en los ovocitos de la raya guitarra también fueron propuestos por Maruska et al. (1996) para $D$. sabina y la descripción de la glándula oviducal se ajusta parcialmente a lo descrito por Wenbin \& Shuyuan (1993), quienes citan dos zonas, la primera, morada, corresponde a la porción anterior que secreta albúmina y otra posterior, rosada, que produce la cáscara de recubrimiento del huevo.
La estructura y composición del sistema reproductor masculino de $R$. percellens fueron semejantes a los de $R$. horkelli (Martin \& Calliet 1988) de Brasil y $R$. hynnycephalus (Wenbin \& Shuyuan 1993) de aguas cálidas del sureste de China. Pratt (1988) sostiene que la estructura compuesta del testículo de los batoideos es enigmática, Potamotrygon muestra un testículo claramente lobular con desarrollo radial, D. americana y M. californica tienen testículos lobulados con desarrollo compuesto a través de cada lóbulo e Himantura imbricata presenta de tres a cinco lóbulos por testículo. Lo anterior indica que en rayas tal vez hay más de dos tipos estructurales gonadales y la forma del testículo puede constituirse en un estado sinapormófico para esta familia; así mismo una disposición estructural diferente y el oviparismo pueden reflejar simplesiomorfías entre las rayas del superorden Rajioidei, aspecto que debe ser estudiado a profundidad.

La presencia de vellosidades en las paredes uterinas (trofonemata), que liberan la 'leche uterina' o histiotrofo, rico en proteínas y lípidos, representa una mejor transferencia de nutrientes para los embriones, respecto a las que cuentan con sacos vitelinos únicamente y han sido observadas también en $R$. hynnicephalus (Wenbin \& Shuyuan 1993) y R. cemiculus (Seck et al. 2004). Los huevos de la raya guitarra al ser fecundados se recubren de una delgada capa córnea ambarina, como lo describió Villavicencio (1995) para Z. exasperata; no obstante, Villavicencio-Garayzar (1995) sobre esta especie dice no haber observado trofonemata, clasificandola como vivípara obligada lecitotrófica o como vivípara uterina con los compartimentos no formados, del tipo II úterosaco vitelino (Otake 1990).

Rhinobatos percellens al parecer produce entre dos y cuatro embriones por cada época reproductiva, esta fecundidad es baja si se tienen en cuenta los registros para $R$. horkelli con cuatro a doce embriones (Lessa 1982, Lessa et al. 1986), R. halavi cuatro a siete; $R$. djiddensis cuatro a ocho (Melouk 1949 fide Villavicencio 1995), dos a once en $R$. annulatus (Rossouw 1983 fide Villavicencio 1995) y entre seis y 16 en $R$. productus; el embrión más pequeño encontrado con la cubierta rota fue de 29,5 mm, por encima de la talla máxima embrionaria para $R$. productus, 21,5 mm (Villavicencio 1993a). La talla de nacimiento puede estar entre 174 y $170 \mathrm{~mm}$, que correspondió al macho y hembra más pequeño capturado libre, por debajo de la talla de nacimiento de $R$. productus, estimada por Villavicencio (1993a) en $240 \mathrm{~mm}$.

La ausencia de tendencias marcadas en los índices biológicos de $R$. percellens coincide con Seck et al. (2004) para R. cemiculus y D. sabina por Maruska et al. (1996), 
para las que se describe un comportamiento estable durante el año. Por ello, en los machos, la vesícula seminal y el epididimo resultan ser más informativos en la interpretación de la dinámica reproductiva de los batoideos, mientras que en las hembras, las reservas del hígado parecen ser dirigidas a la producción permanente de huevos. Esto confirma, como lo dicen Maruska et al. (1996), que los índices biológicos, si bien ilustran las variaciones en los tamaños de las gónadas, no estiman la actividad reproductiva y deben relacionarse con precaución con los picos reproductivos.

La talla a la que las hembras de raya guitarra alcanzaron su madurez fue muy cercana a la registrada por Seck et al. (2004) en $R$. cemiculus, superarando el $66,5 \%$ de su talla máxima. La presencia y estado de desarrollo de los embriones hace pensar que los nacimientos se dan entre febrero y marzo y de octubre a noviembre, cuando se comienzan a incrementar las temperaturas del agua (Franco 2005). Es así como la sincronización del periodo de gestación con los ciclos de temperatura y producción de alimento en el margen costero de Santa Marta, como en otras partes de mundo, dan la ventaja adaptativa de tener un mayor crecimiento de los neonatos (Villavicencio 1993a) y una menor abundancia de depredadores (Villavicencio 1995).

El ciclo reproductivo de $R$. percellens coincide con el de $R$. horkelli, $R$. annulatus (Villavicencio 1995), $R$. rhinobatos (Ismen et al. 2007) y $R$. productus (Villavicencio 1993a). En un mismo periodo de tiempo, de manera simultánea al desarrollo embrionario, crecen los ovocitos de la siguiente progenie, los cuales son fecundados en los días siguientes a la expulsión de los neonatos y permanecen sin desarrollo embrionario por ocho meses hasta que reinician su crecimiento el siguiente año; y aunque presenta las mismas etapas propuestas para otros rinobátidos, su progresión es inversa con respecto a los ciclos descritos en el hemisferio norte (Villavicencio 1993a, Seck et al. 2004), dándose un periodo de reproducción activa entre octubre y abril y un receso de mayo a septiembre.

Se propone entonces para la raya guitarra un ciclo reproductivo conformado por dos etapas principales, en la primera, mayo a septiembre, hay un aparente receso de la actividad reproductiva, debida a la ausencia definitiva de hembras con ovocitos maduros, huevos uterinos y/o embriones; en este periodo, los índices biológicos mantienen comportamientos estables y prima en la región la época lluviosa. La segunda etapa parece iniciarse en octubre, con presencia de hembras maduras conteniendo ovocitos maduros, huevos intrauterinos y disponibilidad de machos maduros para la cópula. En octubre las hembras contienen embriones y los índices gonadosomáticos alcanzan sus mayores valores. En diciembre, febrero, marzo y abril este patrón se mantiene, incluso en diciembre aparecen hembras en estado de postparto, indicando que probablemente ocurre una primera cópula en diciembre y una segunda entre febrero y marzo. Las hembras dejan el área hasta septiembre cuando volvieron a capturarse; durante este periodo persistieron en el área animales juveniles, que pudieron haber nacido en diciembre o previa la cópula de marzo, lo que confirma los periodos de gestación propuestos en este documento. El ciclo aquí propuesto coincide con el de Lessa (1982) para la misma especie al norte de Brasil, con una gestación corta y dos nacimientos por año, utilizando las aguas costeras de Caicara, como sitios de cría primarios (hábitat donde se dan nacimientos y los juveniles pueden permanecer por un corto tiempo de semanas o meses) y secundarios (lugares donde se encuentran juveniles y luego alcanzar su madurez), lo cual también fue descrito para $R$. percellens en playa Salguero, en el Caribe de Colombia. El desarrollo embrionario activo de los rinobátidos, en general, es de tres a cuatro meses, no obstante $R$. cemiculus, al parecer, gesta entre cinco y ocho meses, quedando sin desarrollarse por cuatro meses; esto ocurre cuando el agua es fría en Senegal (Capape \& Zaouali 1999, Seck et al. 2004); la gestación dura entre cuatro y nueve meses para $R$. rhinobatos en el Mediterráneo este, donde también se da la diapausa de diciembre a marzo (Ismen et al. 2007). Lessa (1982), en aguas brasileras, registró la reactivación del desarrollo embrionario para $R$. horkelli cuando las condiciones ambientales son más favorables (de diciembre a marzo).

Los rinobátidos, como los elasmobranquios en general, se consideran fauna incidental de las pesquerías artesanales e industriales de Colombia y aunque su valor económico es bajo en la actualidad, existe riesgo de una dramática disminución de sus poblaciones, frente a la presión de pesca causada por su captura ocasional. Por lo anterior, los resultados del presente estudio centran la atención en esta especie que, como otras, está bien representada en el margen costero del Magdalena; aunque sus poblaciones no parecen reflejar cambios drásticos en su estructura, como producto de su explotación, estas deben ser estudiadas antes de mostrar signos de deterioro.

\section{Agradecimientos}

Este trabajo se enmarcó en los proyectos 'Aspectos biológicos de algunos rajiformes en Santa Marta (Caribe colombiano)', ejecutado gracias al apoyo logístico y financiero de la Universidad de Bogotá Jorge Tadeo Lozano, Facultad de Ciencias Naturales, Programa de Biología Marina, Sede Santa Marta y la Dirección de 
Investigaciones, y 'Biología reproductiva de cuatro especies de batoideos: una contribución histológica', financiado por la Fundación para la Promoción de la Ciencia y la Tecnología del Banco de la República. Agradecimientos especiales a los pescadores de playa Salguero Ignacio Acosta, Iván Urieles y a sus familias. Contribución 010 del Grupo de Investigación en Peces del Caribe (GIPECA-UJTL) y 317 del Centro de Investigaciones en Ciencias del Mar de la Universidad Nacional de Colombia. Agradecimiento al comité evaluador anónimo que con sus aportes contribuyó sustancialmente en el mejoramiento del documento.

\section{Literatura citada}

Acevedo K, J Bohórquez-Herrera, F Moreno, C Moreno, E Molina, M Grijalba-Bendeck \& P Gómez-Canchong. 2007. Tiburones y rayas (Subclase Elasmobranchii) descartados por la flota de arrastre camaronero en el Caribe de Colombia. Acta Biológica Colombiana 12(2): 71-81.

Bonfil R. 1994. Overview of world elasmobranch fisheries. FAO Fisheries Technical Paper 341: 1-119.

Capapé C \& J Zaouali. 1999. Distribution and reproductive biology of the blackchin guitarfish Rhinobatos cemiculus (Pisces: Rhinobatidae) in Tunisian waters (Central Mediterranean). Australian Journal of Marine and Freshwater Research 45: 551-561.

Cervigón F \& AAlcalá. 1999. Los peces marinos de Venezuela. Tiburones y Rayas Vol V, 230 pp. Fundación Científica los Roques, Caracas.

Conrath C. 2005. Reproductive biology. En: Musik J \& R Bonfil (eds). Management techniques for elasmobranch fisheries. FAO Fisheries Technical Paper 474: 1-251.

Franco A. 2005. Oceanografía de la ensenada de Gaira: El Rodadero, más que un centro turístico en el Caribe Colombiano, 56 pp. Fundación Universidad Jorge Tadeo Lozano, Bogotá.

Hamlett WC, J Musick, A Eulitt, R Jarrell \& M Kelly. 1996. Ultrastruture of uterine trophonemata, accommodation for uterolactation and gas exchange in the southern stingray, Dasyatis americana. Canadian Journal of Zoology 74: 1431-1443.

Hamlett WC, M Jezior \& R Spieler. 1999. Ultrastructural analysis of folliculogenesis in the ovary in the yellow spotted stingray Urolophus jamaicensis. Annals of Anatomy 181(2): 159-172.

Holden M \& D Raitt. 1975. Manual de ciencia pesquera, métodos para investigar los recursos y su aplicación. Organización de las Naciones Unidas para la agricultura y la alimentación. Vol 2. Roma. 221 pp.

Díaz JM \& DI Gómez López (eds). 2000. Programa Nacional de Investigación en Biodiversidad Marina y Costera. Plan de Acción 2001-2010, 83 pp. INVEMAR/FONADE/MMA, Santa Marta.
Ismen S, C Yigin \& P Ismen. 2007. Age, growth, reproductive biology and feed of the common guitarfish (Rhinobatos rhinobatos Linnaeus, 1758) in Iskenderun Bay, the eastern Mediterranean Sea. Fisheries Research 84: 263-269.

Jezior MR \& WC Hamlett. 1994. Ultrastructure of the uterus and shell gland in the yellow spotted ray: A model for reproductive toxicology. Notre Dame Undergraduate Research Symposium, University of Notre Dame, Notre Dame, Indiana, May 1994, Notre Dame Science Quarterly 23(4): 9-11.

Lessa R. 1982. Biologie et dynamique des poulations de Rhinobatos horkelii du plateau continental de Rio Grande do Sul (Brasil). Ph. D. Thesis, Université de Bretagne Occidentale, Brest, 238 pp.

Lessa R, C Vooreen \& J Lahaye. 1986. Desenvolvimiento e ciclo sexual das femeas, migrações e fecundidade da viola Rhinobatos horkelii (Müller y Henle, 1841) du Su do Brasil. Atlántica 8: 5-34.

Liu K, C Chen, T Liao \& S Joung. 1999. Age, growth, and reproduction of the pelagic Thresher shark, Alopias pelagicus in the northwestern Pacific. Copeia 1: 68-74.

Martin L \& G Cailliet. 1988. Age and growth determination of the bat ray, Myliobatis californica Gill, in Central California. Copeia 1988 (3): 762-773.

Martoja R \& M Martoja-Pierson. 1970. Técnicas de Histología Animal, 350 pp. Toray-Masson, Barcelona.

Maruska K, C Cowie \& T Tricas. 1996. Periodic gonadal activity and protracted mating in elasmobranch fishes. Journal of Experimental Zoology 276: 219-232.

Mollet H, G Cliff, H Pratt \& J Stevens. 1999. Reproductive biology of the female shortfin mako, Isurus oxyrhinchus Rafinesque, 1810, with comments on the embryonic developent of lamnoids. Fishery Bulletin 98: 299-318.

Natanson L \& G Cailliet. 1986. Reproduction and development of the Pacific Angel shark, Squatina californica, off Santa Barbara, California. Copeia 1986(4): 987-994.

NOAA. 1991. Fishery management plan for sharks of the Atlantic Ocean, 47 pp. National Marine Fisheries Service, National Oceanic and Atmospheric Administration, U.S. Department of Commerce, Washington.

Otake T. 1990. Classification of reproductive modes in sharks with comments on female reproductive tissues and structures. En: Pratt HL, SH Gruber \& T Taniuchi (eds), Elasmobranchs as living resources: Advances in the biology, ecology, systematics, and the status of the fisheries. NOAA Technical Report NMFS 90: 111-130.

Pratt H. 1988. Elasmobranch gonad structure: A description and survey. Copeia 1988(3): 719-729.

Saila SB, CW Recksieck \& MH Prager. 1988. Basic Fisheries Science Programs, 230 pp. Elsevier, Nueva York.

Seck A, T Diatta, M Diop, O Guélorget, D Reynaud \& C Capapé. 2004. Observations on the reproductive biology of the Blackchin guitarfish, Rhinobatos cemiculus E. Geoffroy Saint-Hilaire, 1817 (Chondrichthyes, 
Rhinobatidae) from the coast of Senegal (Eastern Tropical Atlantic). Scientia Gerundensis 27: 19-30.

Snelson F, S Williams-Hooper \& T Schmidt. 1988. Reproduction of the Atlantic Stingray, Dasyatis sabina, in Florida coastal lagoons. Copeia 1988(3): 729-739.

Téllez L, C Vargas \& M Grijalba-Bendeck. 2006. Algunos aspectos biológicos de Urotrygon venezuelae Schultz, 1949 (Elasmobranchii, Rajiformes, Urolophidae), capturada en playa Salguero, Santa Marta, Caribe de Colombia. Revista UDCA Actualidad \& Divulgación Científica 9(2): 75-87.

Timmons M \& R Bray. 1997. Age, growth, and sexual maturity of shovelnose guitarfish, Rhinobatos productus (Ayres). Fishery Bulletin 95: 349-359.

Tresierra A \& Z Culquichicón. 1993. Biología pesquera, 432 pp. Consejo Nacional de Ciencia y Tecnología, Lima.

Villavicencio C. 1993a. Biología reproductiva de Rhinobatos productus (Pisces: Rhinobatidae), en bahía Almejas, Baja California Sur, México. Revista de Biología Tropical 41(3): 777-782.

Villavicencio C. 1993b. Observaciones sobre la biología reproductiva de Narcine brasiliensis (Olfers) (Pisces: Narcinidae), en Bahía Almejas, B.C.S. México. Revista de Investigación Científica 4(1): 95-99.
Villavicencio C. 1995. Distribución temporal y condición reproductiva de las rayas (Pisces: Batoidei), capturadas comercialmente en bahía Almejas, B.C.S., México. Revista de Investigación Científica 6(1-2): 1-12.

Villavicencio-Garayzar C. 1995. Biología reproductiva de la guitarra pinta, Zapterix exasperata (Pisces: Rhinobatidae), en bahía Almejas, Baja California Sur, México. Ciencias Marinas 21(2): 141-153.

Wenbin Z \& Q Shuyuan. 1993. Reproductive biology of the guitarfish, Rhinobatos hynnicephalus. Environmental Biology of Fish 38: 81-93.

White W, M Platell \& I Potter. 2001. Relationship between reproductive biology and age composition and growth in Urolophus lobatus (Batoidea: Urolophidae). Marine Biology 138: 135-137.

Wourms JP. 1981. Viviparity: Maternal - fetal relationships in fishes. American Zoologist 21: 473-515.

Recibido el 23 de noviembre de 2007 y aceptado el 30 de junio de 2008 